(C) 2015. This manuscript version of Effect of Pressure and Temperature on Interfacial

Tension of Poly lactic acid melt in supercritical carbon dioxide is made available under the CC-BY-NC-ND 4.0 license http://creativecommons.org/licenses/by-nc-nd/4.0/

This document is the accepted manuscript version of a published article. Published by Elsevier in the journal "Thermochimica Acta" volume 609, http://dx.doi.org/10.1016/j.tca.2015.04.005

\title{
Effect of Pressure and Temperature on Interfacial Tension of Poly lactic acid melt in supercritical carbon dioxide
}

\footnotetext{
K.Sarikhani $^{a, b}, K_{. J e d d i}{ }^{a, b}$, R.B. Thompson ${ }^{b, c}$, C.B.Park ${ }^{d}$, P.Chen $^{a, b^{*}}$

${ }^{a}$ Department of Chemical Engineering, University of Waterloo, 200 University Avenue, Waterloo, Ontario, Canada N2L 3G1 ${ }^{b}$ Waterloo Institute for Nanotechnology, University of Waterloo, 200 University Avenue, Waterloo, Ontario, Canada N2L 3G1

${ }^{c}$ Department of Physics and Astronomy, University of Waterloo, 200 University Avenue, Waterloo, Ontario, Canada N2L 3G1

${ }^{d}$ Microcellular Plastics Manufacturing Laboratory, Department of Mechanical and Industrial Engineering, University of Toronto, 5 King's College Road, Toronto, Ontario, Canada M5S $3 G 8$
}

\section{Graphical Abstract}

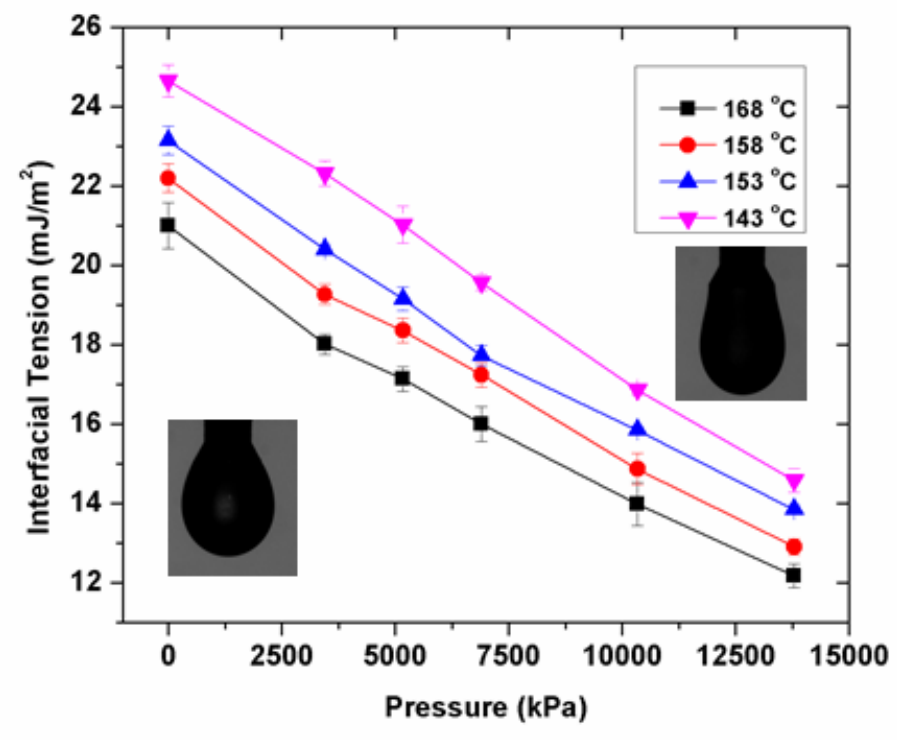

\section{Highlights}

- Surface tension of poly lactic acid was measured at high temperatures using Axisymmetric drop shape analysis profile (ADSA-P) pendant drop technique.

- Effect of supercritical carbon dioxide pressure on interfacial tension of poly lactic acid was investigated.

\footnotetext{
${ }^{*}$ Corresponding author. Tel.: 519-888-4567 x35586

E-mail address: p4chen@uwaterloo.ca (P. Chen).
} 
- Interfacial tension decreased with increasing temperature and pressure.

- Polymer melt with Bond number between 0.36-0.48 formed stable drops.

\begin{abstract}
The interfacial tension of poly lactic acid (PLA) melt is measured in supercritical carbon dioxide $\left(\mathrm{CO}_{2}\right)$ at the temperature range of $143{ }^{\circ} \mathrm{C}$ to $168{ }^{\circ} \mathrm{C}$ and $\mathrm{CO}_{2}$ pressures up to 2000 psi, using Axisymmetric Drop Shape Analysis Profile (ADSA-P). The results show a decrease in interfacial tension with increasing temperature and pressure. However, the interfacial tension dependency on temperature at high pressures decreases because of a reduction in $\mathrm{CO}_{2}$ solubility at high temperatures. The relationship between the interfacial tension and the density-difference of polymer-supercritical $\mathrm{CO}_{2}$ mixtures is also examined by the generalized Macleod equation. Moreover, the range of stability for the melted drop, in interfacial tension measurements, is obtained by dimensionless Bond number. The results indicate the validity of the measurements for Bond number between 0.36 and 0.48 .
\end{abstract}

Keywords: poly lactic acid, interfacial tension, supercritical carbon dioxide, high - temperature pendant drop 


\section{Introduction}

The interfacial and surface tension of polymers is a key thermodynamic parameter in various applications such as polymer blending [1], wetting [2], dispersion of particles or fibres in polymers [3], and polymer foaming [4]. Numerous methods can be used to measure the interfacial tension of polymers. Among them, Axisymmetric Drop Shape Analysis (ADSA) is a powerful and precise technique for the measurement of surface tensions and contact angles of liquids and solids. The technique can be applied for various systems such as pendant drop, sessile drop, and captive bubbles [5]. Generally, ADSA methods work based on the numerical fit between the profile obtained from the shape of drops or bubbles and the theoretical drop shape from the Laplace equation of capillarity [6].

Even though the importance of surface tension and interfacial tension of polymer melts is evident in many applications, data related to high-pressures and high-temperatures are rarely reported in the literature because of the high viscosities, difficulties of forming the drop in high temperatures, thermal degradation, and lack of PVT data at high temperatures and high pressures.

In foam materials, the interfacial tension between a dense continuum and the dispersed voids plays a critical role in the structure and properties of final products [7]. Among foams, polymeric foams have attractive mechanical, energy-absorbing, and thermal-insulation properties [8]. One promising polymer in the foam industry is polylactide (PLA); a biodegradable and biocompatible polyester derived from lactic acid [9]. Because of its high modulus, high strength and appropriate clarity, this aliphatic thermoplastic polyester can be seen as a potential replacement for petroleum-based synthetic polymers [10]. Besides its decent mechanical 
properties, PLA has significant environmental merits compared with other commodity polymers, including its renewable agricultural source, the consumption of carbon dioxide during its production, its compostability and recyclability $[9,11]$.

Polymeric foams are made of either chemical blowing agents or physical blowing agents. The former have drawbacks such as environmental issues and processing limitations. On the other hand, physical blowing agents have shown promise in producing microcellular polymer foams. Among physical blowing agents, supercritical fluids such as carbon dioxide $\left(\mathrm{CO}_{2}\right)$ and nitrogen are both suitable candidates to substitute for conventional physical blowing agents like chlorofluorocarbons (CFCs) [12]. Two steps are involved in polymer foaming using physical blowing agents: nucleation and growth. The first step includes absorption of enough gas molecules in the polymer matrix to reach a thermodynamically unstable threshold to be able to nucleate a bubble bigger than a critical size. The second involves growth of the bubbles [7].

In order to improve the foaming behaviour of microcellular foams, one can increases the number of nucleating sites through manipulating surface tension. Based on classical nucleation theory (CNT), the nucleation rate is inversely related to the exponential cubic power of surface tension $[4,13]$; lowering surface tension decreases the energy barrier for cell nucleation and exponentially increases the number of cells, leading to higher cell densities. Additionally, lower surface tensions lead to a smaller cell size since critical cell size is directly related to surface tension [7]. For the above mentioned reasons, a study of the effect of processing conditions (temperature and pressure) on the interfacial tension of PLA and the blowing agent $\left(\mathrm{CO}_{2}\right)$ is indispensable. Despite the importance of foaming and blending of 
biodegradable polymers such as PLA with supercritical $\mathrm{CO}_{2}\left(\mathrm{SCCO}_{2}\right)$, there is very scarce data for interfacial and surface tension of PLA at high temperatures and high pressures [14]. Mahmood et. al [14], have reported the interfacial tension of PLA and supercritical $\mathrm{CO}_{2}$ using a sessile drop method at temperatures higher than melting point for PLA with different Dcontents. In the current work, surface tension measurement of a different grade of PLA with different molecular weight and D-content is measured using a different method (pendant drop). Surface tension of PLA at high temperatures and the interfacial tension of PLA and $\mathrm{SCCO}_{2}$ are investigated in the melting point window and under foaming processing conditions using the pendant drop method. The study of PLA interfacial tension near the melting point seems essential because not only do most polymeric foams form and stabilize in temperatures in the range of the melting point, but also the solubility of supercritical $\mathrm{CO}_{2}$ in the polymer may vary at temperatures around and below the melting point of the polymers. The results shows that unlike polymers with high level of crystallinity (such as high-density polyethylene (HDPE)) [15,16], no anomalous behaviour in interfacial tension due to crystallization is observed in PLA.

\section{Materials and Methods}

\subsection{Materials}

In this work, PLA under the trade name of PLA-2002D with $\mathrm{M}_{\mathrm{n}}=$ $100 \mathrm{~kg} / \mathrm{mol}$ and D-content of $4.5 \%$ was kindly provided by NatureWorks. Carbon dioxide chromatographic grade (purity $99.99 \%$ ) was purchased from PRAXAIR, Canada. 


\subsection{Solubility Measurement}

The solubility of $\mathrm{CO}_{2}$ in the PLA melts was obtained using a Magnetic Suspension Balance (MSB) from Rubotherm GmbH as the schematic shows in Figure 1. Details about the experimental apparatus and procedure can be found in previous publications [17-19], however, a brief overview of the solubility measurement is as follows. At vacuum $(P=0)$ and temperature $T$, polymer pellets were weighed as $W(0, T)$ from the balance readout. After adjustment of pressure and completion of gas sorption in the polymer by reaching saturation point, the weight of the saturated polymer melt was recorded from the readout on the MSB, and was defined as $W(P, T)$ at pressure $(P)$ and temperature $(T)$. Then, using the obtained weights, the amount of gas dissolved in the polymer melt, $\mathrm{Wg}$, was calculated as below [20]:

$$
W_{g}=W(P, T)-W(0, T)+\rho_{C O_{2}}\left(V_{B}+V_{P}+V_{S}\right)
$$

where the density of the gas, $\rho_{\mathrm{CO}_{2}}$ was obtained using a MSB [18]; $V_{B}$ is the volume of the sample holder, $V_{P}$ is the volume of the neat polymer (without gas dissolution and volume swelling) at pressure $P$ and temperature $T$. The latter was obtained from the mass and specific volume $\left(V_{s p}\right)$ based on Tait's PLA equation. The term $V_{S}$ is the swollen volume of the polymer melt due to gas dissolution. 


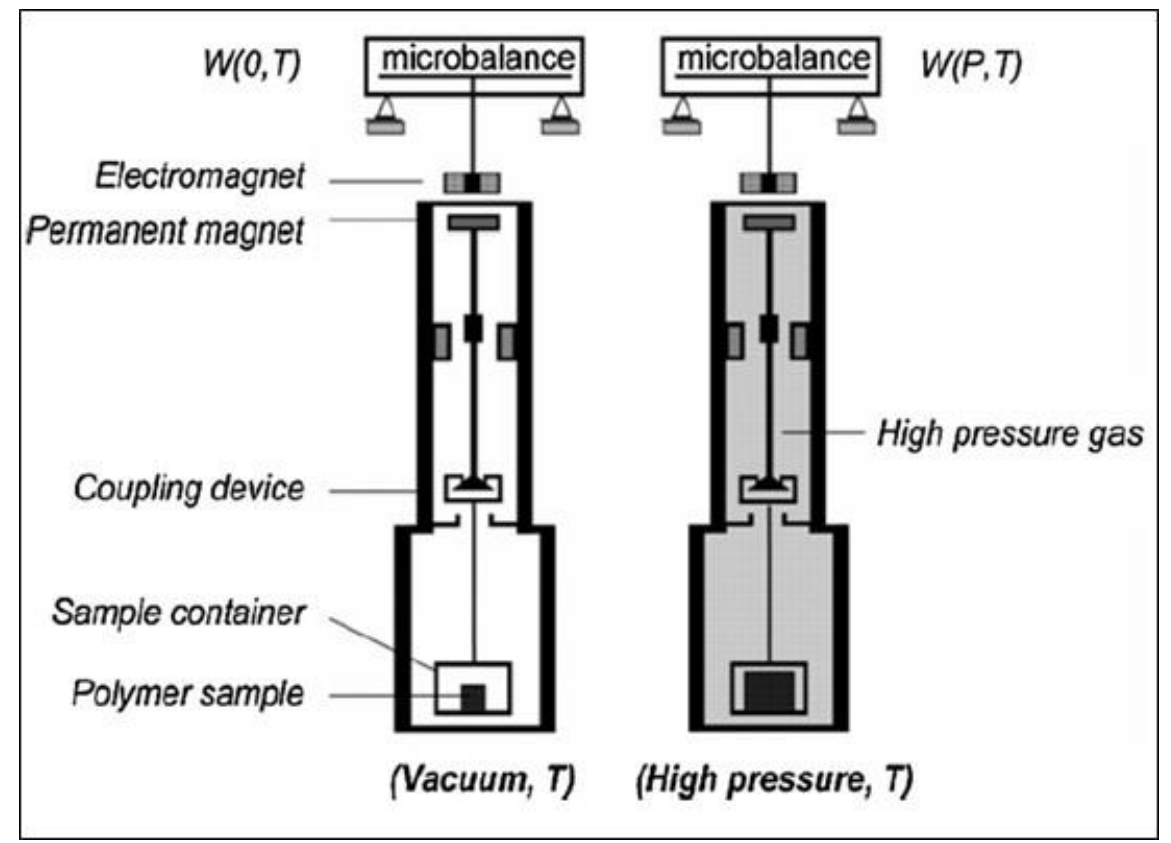

Figure 1. A schematic of the magnetic suspension balance (MSB) [21]

If the volume of swollen polymer $\left(V_{S}\right)$ is not considered, the apparent solubility $X_{\text {apparent }}$ is as follows:

$$
X_{\text {apparent }}=\frac{W(P, T)-W(0, T)+\rho_{\mathrm{CO}_{2}}\left(V_{B}+V_{P}\right)}{\text { mass of sample }}
$$

It is obvious that the apparent solubility is less than the actual solubility. The corrected solubility, $X_{\text {corrected }}$, considering the buoyancy effect , can also be calculated:

$$
X_{\text {corrected }}=X_{\text {apparent }}+\frac{\rho_{\text {gas }} V_{S}}{\text { mass of sample }}
$$

Theoretically, an approximation of the swollen volume can be obtained using the following calculation: 


$$
V_{S}=\left[(1+X)+v_{p, \text { mixture }}-v_{p, p u r e}\right] \times m
$$

where $X$ is the gas solubility in the polymer melt from the Simha Somcynsky (SS) equation of state (EOS), $m$ is the initial weight of the polymer, $v_{p \text {,pure }}$ is the specific volume of pure polymer that can be obtained from Tait's equation, and $v_{p \text {,mixture }}$ is the specific volume of the polymer/gas mixture at equilibrium that can be calculated using the EOS.

More details about the PVT behavior of the polymer- $\mathrm{CO}_{2}$ mixture can be found in the literature $[19,22]$. In brief, it is as follows. Each measurement at each pressure is recorded until the volume of the polymer- $\mathrm{CO}_{2}$ mixture becomes unchanged. The swollen volume was determined by the ratio between the final equilibrium volume and the initial volume from Tait's equation:

$$
S_{w}=\frac{V\left(T, P, t_{e q}\right)}{V\left(T, P, t_{\text {in }}\right)}=\frac{V\left(T, P, t_{e q}\right)}{m_{\text {sample }} v(T, P)}
$$

where $V\left(T, P, t_{e q}\right)$ is the measured equilibrium volume of the polymer- $\mathrm{CO}_{2}$

mixture at temperature $T$, pressure $P$, and equilibrium time $t_{e q} V\left(T, P, t_{\text {ini }}\right)$ is the volume of the PLA sample under the same conditions, taken from Tait's equation.

\subsection{Surface Tension Measurement}

Axisymmetric drop shape analysis profile (ADSA-P) technique was used to measure the surface tension of PLA at various temperatures and pressures ranging from 143 to $168{ }^{\circ} \mathrm{C}$. The surface tension of the polymer samples 
was measured by fitting the shape and dimensions of the menisci, obtained through image capturing, to the theoretical drop profile based on the Laplace equation of capillarity:

$$
\Delta P=\gamma\left(\frac{1}{R 1}+\frac{1}{R 2}\right)
$$

In order to provide processing conditions for surface tension measurements, a high-temperature and high-pressure chamber was designed as explained previously $[15,23]$. The optical viewing chamber is a stainless steel cylinder equipped with an electrical band heater and temperature controller. The chamber is a hollow cylinder, with an inner diameter of 30 $\mathrm{mm}$ and length of $25 \mathrm{~mm}$, and two optical-quality sapphire windows (Meller Optics, Inc.) that make it possible to observe the pendant drop of polymer melt during the experiment.

Before starting the experiments, the accuracy of the technique was tested using a drop of pure water, and the value of $72.12 \pm 0.11 \mathrm{~mJ} / \mathrm{m}^{2}$ was consistent for all the measurements. This agrees with a well-established literature value of water surface tension at $23^{\circ} \mathrm{C}$ [24]. A small amount of polymer, $~ 0.004-0.006 \mathrm{~g}$, was attached to the tip of a stainless steel rod with a diameter of $1 \mathrm{~cm}$ and a polished tip to avoid asymmetric drop formation. The method used here has advantages over using drops formed by heating polymer in the capillary tube of a syringe: it eliminates the capillary rise and necking effects, besides allowing for a known system density. To measure the density of the polymer-gas mixture, the volume of one drop was obtained from the pendant drop profile using ADSA software [25] and used to calculate the density of polymer melts at different pressures and 
temperatures, after the initial weight of the polymer and amount of absorbed supercritical carbon dioxide had been obtained by solubility measurements. The density is an input for surface tension measurement and is introduced through the capillary constant: $C=\frac{\Delta \rho g}{\gamma}$, where $\mathrm{C}$ is the capillary constant, $\Delta \rho$ is the density difference between the polymer and the supercritical fluid, $\gamma$ is interfacial tension, and $g$ is gravity's acceleration. The simultaneous measurement of interfacial tension includes introduction of the density of the sample after measurement of its volume. The results can be recalculated using the new density through the capillary constant [25-27].

\subsection{Differential Scanning Calorimetry}

The thermal behavior of PLA at atmospheric pressure was performed using Differential Scanning Calorimeter (DSC), Q2000 (TA Instruments). The PLA sample was heated from room temperature to $200{ }^{\circ} \mathrm{C}$ at a heating rate of $10 \mathrm{~K} / \mathrm{min}$ and then equilibrated at $190{ }^{\circ} \mathrm{C}$ for $5 \mathrm{~min}$ to eliminate the thermal history. Then the sample was cooled to $10^{\circ} \mathrm{C}$ at a rate of $2 \mathrm{~K} / \mathrm{min}$ and eventually the sample was reheated to $190^{\circ} \mathrm{C}$ at a rate of $10 \mathrm{~K} / \mathrm{min}$.

\section{Results and Discussions}

\subsection{Stability of Polymer Melt Drops}

Due to the importance of crystallization on surface tension through preferential adsorption of crystallized polymer particles at interfaces [15,16], the presence of any crystals in the system should be shown. Figure 2 shows isothermal differential scanning calorimetry of the PLA melt at $143{ }^{\circ} \mathrm{C}$. No peak is observed after more than 2.5 hours of experiment denoting the 
absence of crystals at the lowest temperature of the interfacial tension measurements.

In order to find the desired size of the polymer melt drop for pendant drop measurements, the stability of the drops can be investigated through a dimensionless Bond number, as shown in the Equation 7:

$$
B o=\frac{\Delta \rho g R^{2}}{\gamma}
$$

where $\Delta \rho$ is the density difference between $\mathrm{PLA}^{-\mathrm{SCCO}_{2}, g}$ is gravitational acceleration, $R$ is the average radius of curvature of the drop, and $\gamma$ is the interfacial tension between the two phases. Since Bond number is the ratio between buoyancy forces and surface forces, it can determine the range of stability of the drop as well as the validity of surface tension measurements [28]. With this in mind, polymer drops with a wide range of weights at different pressures were formed. Figure 3 shows the range of stability of polymer melt drops based on Bond number. Bond numbers for drops with surface tension value discrepancies of a maximum $2 \%$ from the average are shown. The lower and higher limit for polymer melt drops are 0.37 and 0.48 , respectively. It turns out that for polymer drops with Bond number beyond 0.48, breakage and necking phenomena were happened, and for Bond numbers below 0.37 the accuracy of measurements were questionable due to the formation of "close to spherical" drops and an imbalanced ratio between buoyancy forces and surface forces [28,29]. 


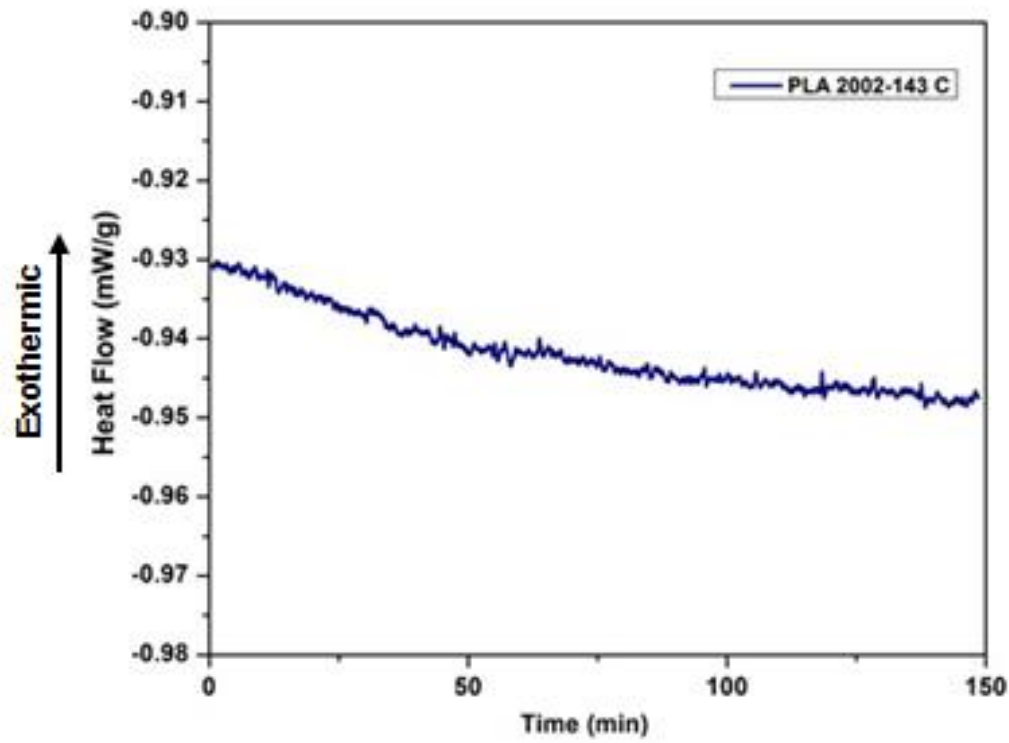

Figure 2. Isothermal differential scanning calorimetry of PLA 2002 sample at $143^{\circ} \mathrm{C}$

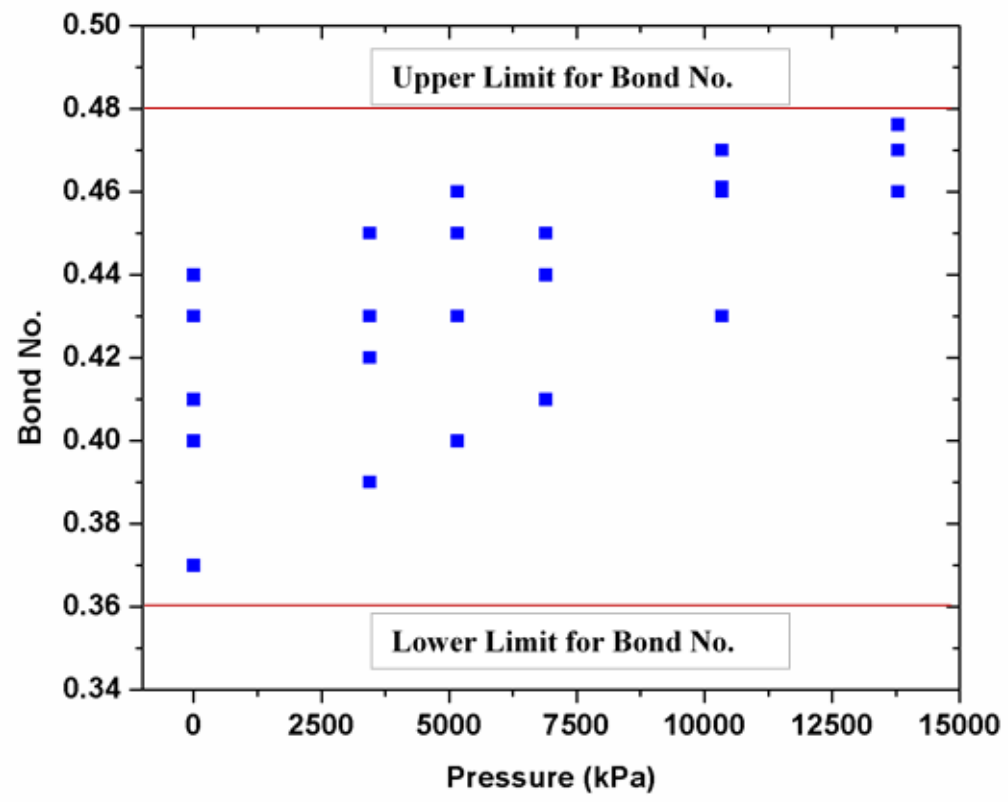

Figure 3. Bond number vs. pressure reflecting the range of stability of polymer drops. 


\subsection{Solubility Measurements}

Like surface tension, solubility is another determining factor in microcellular foam processing and polymer blending [19,30,31]. Knowing solubility, as well as surface tension in the processing range of temperature and pressure, one can decide on the processing window of the desired polymer. Figure 4 presents the solubility data in the pressure range of 500 to 2000 psi for temperatures of $140,150,160^{\circ}$ C. As can be seen from the graph, at a constant temperature, an increase in pressure increases the solubility due to higher dissolution of gas molecules at high pressures. On the other hand, as temperature increases the solubility of $\mathrm{CO}_{2}$ decreases; although there is more free-volume for adsorption of gas molecules at elevated temperatures, the rate of desorption for physisorption is higher [32]. Moreover, a reduction in the polymer viscosity leads to less resistance in retention of gas molecules in polymer melt. Beside the importance of solubility results in the processing of polymers with supercritical $\mathrm{CO}_{2}$, they can be used to simultaneously determine the density of the mixture at high temperatures and pressures; the amount of dissolved carbon dioxide is added to the initial weight of polymer. 


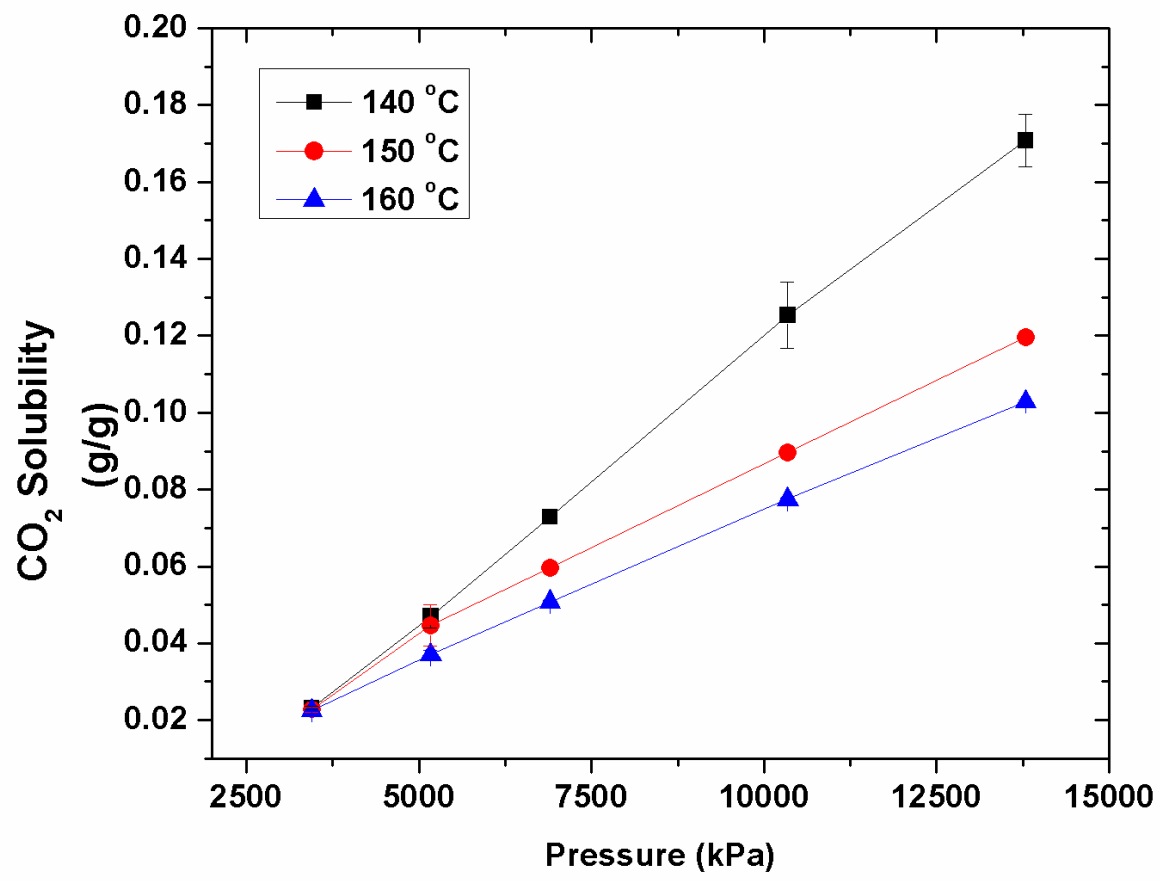

Figure 4. Solubility data of PLA at pressures from 500 psi to 2000 psi and 140,150 , and $160{ }^{\circ} \mathrm{C}$

\subsection{Effect of Pressure and Temperature on Interfacial Tension}

Figure 5 shows the variation of PLA interfacial tension as a function of temperature and pressure. The interfacial tension decreases when both temperature and pressure increase. The reduction in interfacial tension of the polymer and supercritical $\mathrm{CO}_{2}$ caused by increasing temperature happens because of a change in the overall internal energy of the system. It has been shown that the internal energy of mixture of polymers and gases (supercritical $\mathrm{CO}_{2}$ ) is dominant in determining the overall internal energy [33]. Thus, the polymer-gas internal energy determines the reduction in surface tension at higher temperatures. Surface tension can be obtained from a derivative of the free energy with respect to surface area. Free energy is 
defined as $F=U-T S$, where $F$ is free energy, $U$ is internal energy and $S$ is entropy. The entropic contribution improves the mixing of the polymer-gas system, while an increase in internal energy promotes segregation of the polymer and gas. An increase in temperature leads to a reduction in the effective interaction between polymer and gas molecules, and so the internal energy decreases. On the other hand, a reduction in internal energy makes entropy a relatively larger contributor in the free energy and improves mixing across the interface. The interface then becomes more diffuse leading to a lower surface tension.

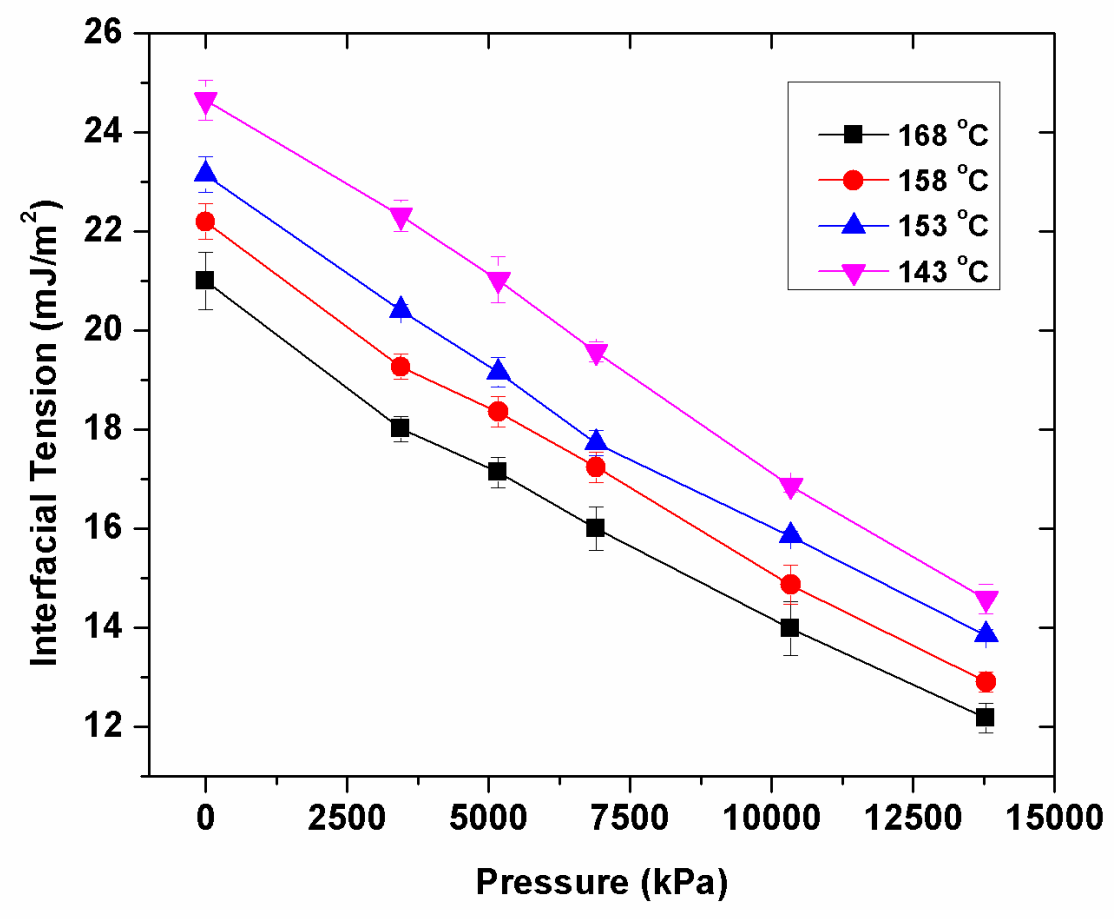

Figure 5. Interfacial tension between polymer and supercritical carbon dioxide at different pressures and temperatures 


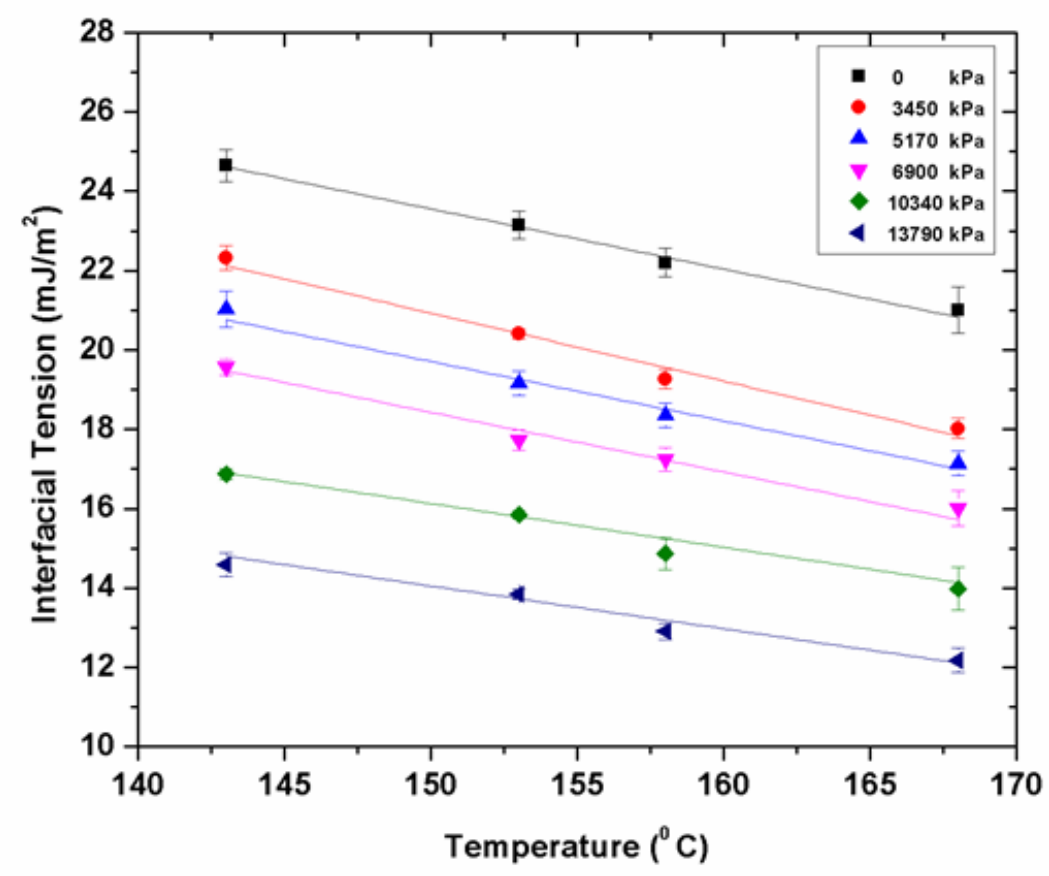

\begin{tabular}{|c|c|}
\hline Pressure $(\mathrm{kPa})$ & Slope \\
\hline 0 & -0.15 \\
\hline 3450 & -0.17 \\
\hline 5170 & -0.15 \\
\hline 6900 & -0.15 \\
\hline 10340 & -0.11 \\
\hline 13790 & -0.10 \\
\hline
\end{tabular}

Figure 6. Interfacial tension of PLA and supercritical $\mathrm{CO}_{2}$ as a function of temperature at different pressures and related slope of linear function at various pressures

In terms of density of the system, for an increase in pressure, the density of the $\mathrm{CO}_{2}$-rich phase increases. As explained in references [23,33], the surface tension drops when the $\mathrm{CO}_{2}$ phase increases in density to be more similar to the density on the polymer side of the interface. Thus one can say the drop in surface tension with increasing pressure is due to a reduction of the density difference between two sides of the interface as the reduction in density difference between phases can be seen in Figure 7.

Based on Figure 6, because of the interaction term between pressure and temperature, the temperature dependency of interfacial tension is different at low and high pressures. It was observed that at low pressures, interfacial tension decreases when temperature increases, while at high pressures, the 
interfacial tension becomes less dependent on the temperature. This independence occurs because at high temperatures and high pressures two competing effects occur: on the one hand, surface tension is reduced because of an increase in temperature, and on the other hand, the solubility of $\mathrm{CO}_{2}$ decreases at high temperatures, as can be seen in Figure 4. The interaction between the two above-mentioned competing factors leads to a diminishing of the temperature effect on the interfacial tension at high pressures $[4,23]$.

\subsection{Density and Surface Tension Relationship}

The trends for density of gas-PLA mixture, density difference between gas-PLA mixture and surrounding (supercritical $\mathrm{CO}_{2}$ ), and density of $\mathrm{CO}_{2}$ at $160{ }^{\circ} \mathrm{C}$ are shown in Figure 7. From the graph it can be seen that the mixture density does not change significantly with increasing pressure since the increase in drop volume due to $\mathrm{CO}_{2}$ dissolution is compensated by an increase in mass owing to $\mathrm{CO}_{2}$ absorption. On the contrary, on the gas side (drop surrounding) the density of $\mathrm{CO}_{2}$ increases with an increase in pressure, the fact which leads to a decrease in the density difference across the interface.

The generalized Macleod equation is used to find the relationship between the interfacial tension and density of polymer-supercritical $\mathrm{CO}_{2}$ mixtures:

$$
\gamma=C\left(\rho_{p}-\rho_{f}\right)^{n}
$$

where $\gamma$ is the interfacial tension between polymer and supercritical $\mathrm{CO}_{2}, \mathrm{C}$ is a constant, $\mathrm{n}$ is Macleod's exponent, and $\rho_{\mathrm{p}}$ and $\rho_{\mathrm{f}}$ are the density of the polymer and the supercritical fluid, respectively. The relationship between 
density and surface tension originate from the dependency of surface tension on the distance between the molecules. In other words, the attractive van der Waals forces lessen according to the $4^{\text {th }}$ power of the intramolecular distances: an increase in a fluid's temperature increases the distance between molecules, and consequently, density decreases [34]. Figure 8 shows the surface tension of polymer-supercritical $\mathrm{CO}_{2}$ as a function of density in logarithmic scale for four temperatures. The results for all the temperatures follow the same trend, and the slope is in range of 1.84 to 1.94. This is higher than the surface tension at atmospheric pressure because of the reduction in conformational restriction at the polymer surface due to the presence of $\mathrm{CO}_{2}$ molecules [23].

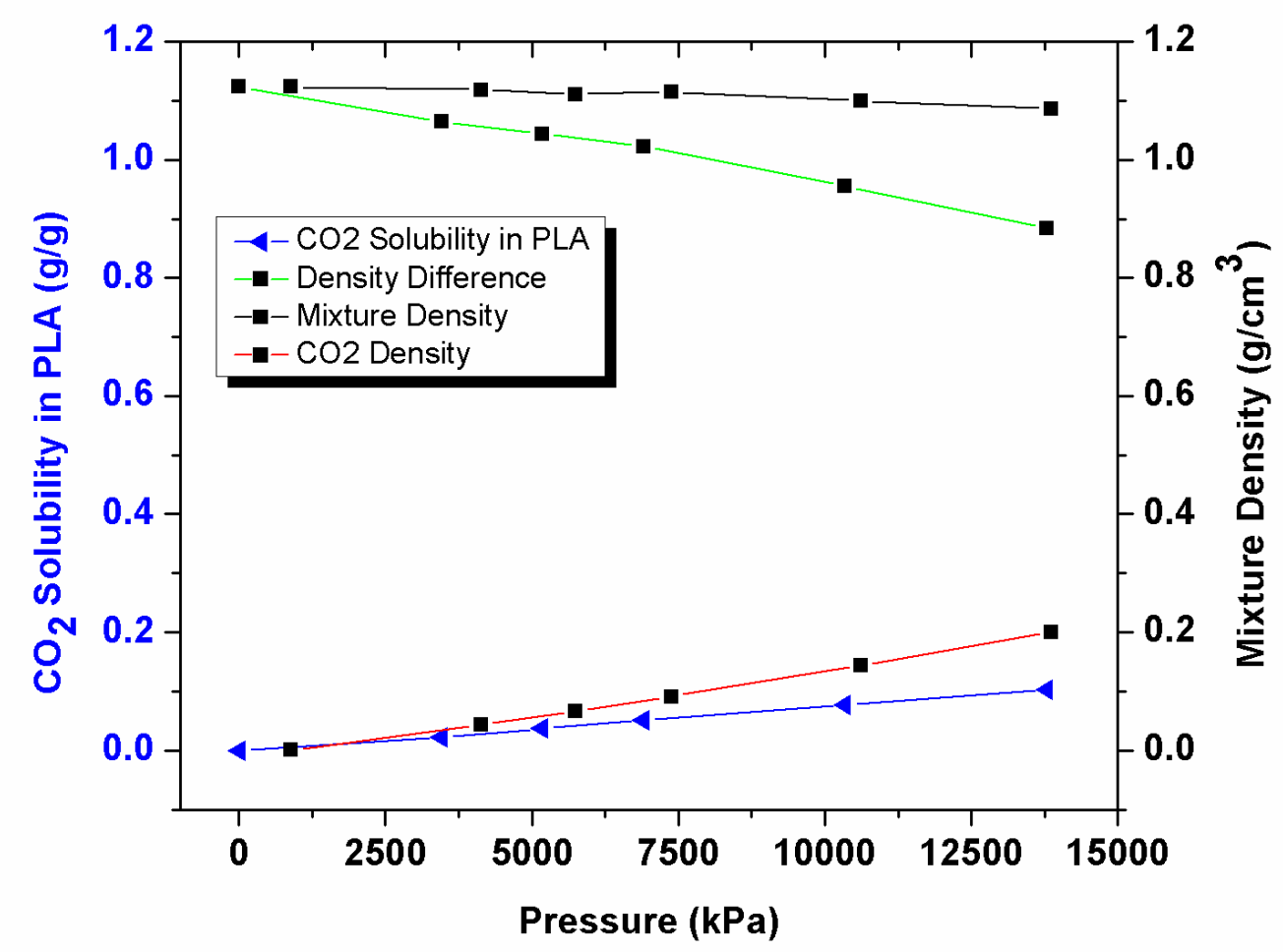

Figure 7. Comparison between density, density difference of $\mathrm{PLA}-\mathrm{CO}_{2}$ mixture, $\mathrm{CO}_{2}$ density (yaxis on the left side), and $\mathrm{CO}_{2}$ solubility (y-axis on the left side) at different temperatures and $160{ }^{\circ} \mathrm{C}$. 


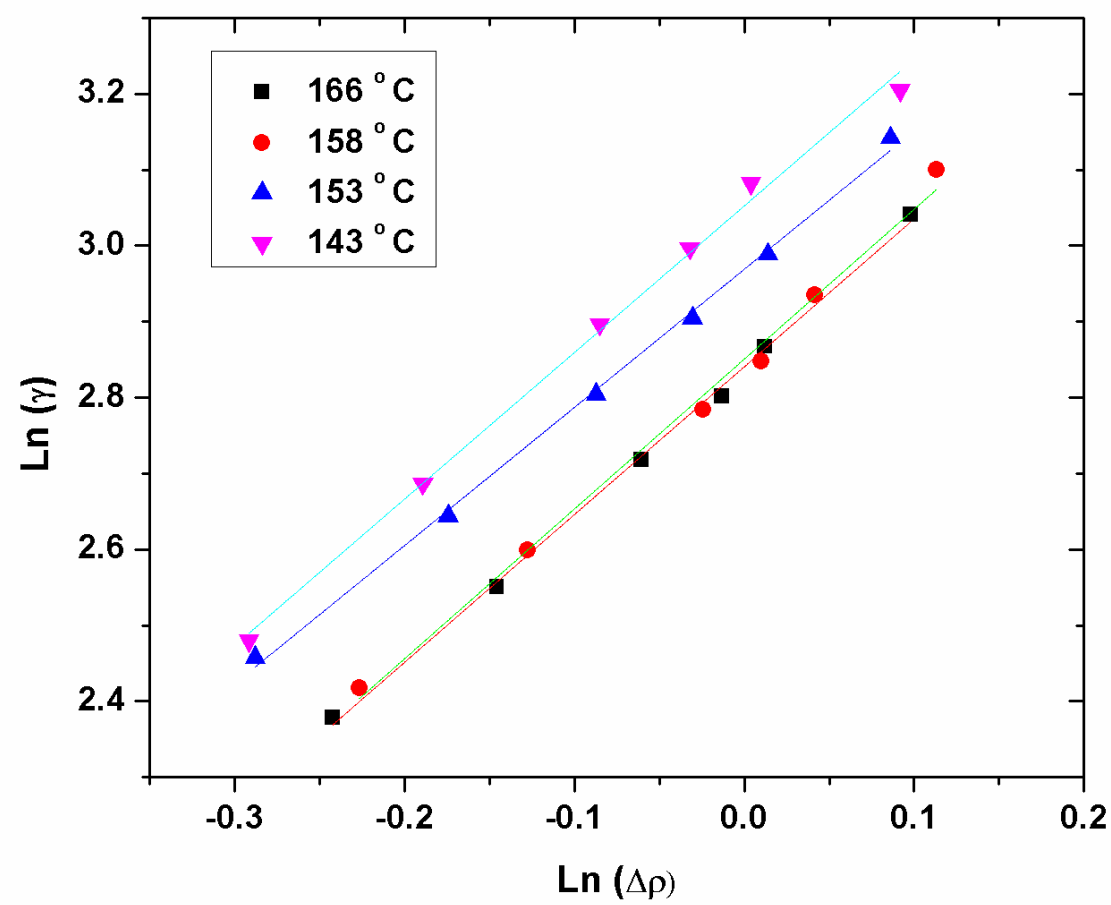

Figure 8. Surface tension vs. density difference of polymer-supercritical $\mathrm{CO}_{2}$ in natural logarithmic scale at different temperatures.

\section{Conclusions}

In this work, we have investigated the dependency of the interfacial tension of poly lactic acid (PLA) in supercritical carbon dioxide on temperature and pressure using the Axisymmetric Drop Shape Analysis Profile (ADSA-P) pendant drop method. The interfacial tension of PLA-supercritical carbon dioxide is measured in the temperature and pressure range of microcellular foaming and blending processes. The results showed a reduction in interfacial tension with increasing temperature and pressure in the ranges of $143^{\circ} \mathrm{C}$ to $168^{\circ} \mathrm{C}$ and 500 to $2000 \mathrm{psi}$, respectively. The interfacial tension dependency on temperature at high pressures decreases because of two 
competing factors: reduction in interfacial tension as a result of an increase in temperature, and the reduction in solubility of $\mathrm{CO}_{2}$ at high temperatures. The relationship between interfacial tension and the density-difference of polymer-supercritical- $\mathrm{CO}_{2}$ mixtures showed similar trends in different temperatures with slopes in the range of 1.84 to 1.94 . In addition, the stability of melted PLA for pendant drop measurements was examined by dimensionless Bond number and it turned out that drops in the range of 0.360.48 were stable.

\section{Acknowledgment}

The authors cordially acknowledge the financial support from the Natural Sciences and Engineering Research Council (NSERC) through the Network for Innovative Plastic Materials and Manufacturing Processes (NIPMMP) and Canada Research Chairs (CRC).

\section{References}

[1] N. Virgilio, P. Desjardins, G. L'Esperance, B.D. Favis, In Situ Measure of Interfacial Tensions in Ternary and Quaternary Immiscible Polymer Blends Demonstrating Partial Wetting, Macromolecules. 42 (2009) 7518-7529. doi:10.1021/ma9005507.

[2] S. Sugiura, M. Nakajima, T. Oda, M. Satake, M. Seki, Effect of interfacial tension on the dynamic behavior of droplet formation during microchannel emulsification., J. Colloid Interface Sci. 269 (2004) 178-185. doi:10.1016/j.jcis.2003.07.031.

[3] V. Khoshkava, M.R. Kamal, Effect of Surface Energy on Dispersion and Mechanical Properties of Polymer/Nanocrystalline Cellulose Nanocomposites., Biomacromolecules. (2013). doi:10.1021/bm400784j.

[4] X. Liao, Y.G. Li, C.B. Park, P. Chen, Interfacial tension of linear and branched PP in supercritical carbon dioxide, J. Supercrit. Fluids. 55 (2010) 386-394. doi:10.1016/j.supflu.2010.06.011. 
[5] M. Hoorfar, M. a. Kurz, a. W. Neumann, Evaluation of the surface tension measurement of axisymmetric drop shape analysis (ADSA) using a shape parameter, Colloids Surfaces A Physicochem. Eng. Asp. 260 (2005) 277-285. doi:10.1016/j.colsurfa.2004.08.080.

[6] O. Río, A. Neumann, Axisymmetric Drop Shape Analysis: Computational Methods for the Measurement of Interfacial Properties from the Shape and Dimensions of Pendant and Sessile Drops., J. Colloid Interface Sci. 196 (1997) 136-147. doi:10.1006/jcis.1997.5214.

[7] N.S.Ramesh. S. Lee, C. B. Park, Polymeric Foams: Science and Technology, Taylor and Francis Group, LLC, 2007.

[8] D. Eaves, Handbook of polymer foams, Rapra Technology Limited, 2004.

[9] R. Auras, B. Harte, S. Selke, An overview of polylactides as packaging materials., Macromol. Biosci. 4 (2004) 835-864. doi:10.1002/mabi.200400043.

[10] S. Saeidlou, M. Huneault, H. Li, C.B. Park, Poly(lactic acid) crystallization, Prog. Polym. Sci. 37 (2012) 1657-1677. doi:10.1016/j.progpolymsci.2012.07.005.

[11] J.R. Dorgan, H.J. Lehermeier, L.-I. Palade, J. Cicero, Polylactides/PP : properties and prospects of an environmentally benign plastic from renewable resources, Macromol. Symp. $175 \quad$ (2001) 55-66. doi:10.1002/1521-3900(200110)175:1<55::aidmasy55>3.0.co;2-k.

[12] K.P. Johnston, S.R.P. Da Rocha, Colloids in supercritical fluids over the last 20 years and future directions, J. Supercrit. Fluids. 47 (2009) 523-530. doi:10.1016/j.supflu.2008.10.024.

[13] H. Li, L.J. Lee, D.L. Tomasko, Effect of Carbon Dioxide on the Interfacial Tension of Polymer Melts, Ind. Eng. Chem. Res. 43 (2004) 509-514. doi:10.1021/ie034092n.

[14] S.H. Mahmood, A. Ameli, N. Hossieny, C.B. Park, The interfacial tension of molten polylactide in supercritical carbon dioxide, J. Chem. Thermodyn. (2014). doi:10.1016/j.jct.2014.02.017.

[15] H. Wei, R.B. Thompson, C.B. Park, P. Chen, Surface tension of high density polyethylene (HDPE) in supercritical nitrogen: Effect of polymer crystallization, Colloids Surfaces A Physicochem. Eng. Asp. 354 (2010) 347-352. doi:10.1016/j.colsurfa.2009.06.005.

[16] R.B. Thompson, C.B. Park, P. Chen, Reduction of polymer surface tension by crystallized polymer nanoparticles., J. Chem. Phys. 133 (2010) 144913. doi:10.1063/1.3493334.

[17] Y. Sato, T. Takikawa, A. Sorakubo, S. Takishima, H. Masuoka, M. Imaizumi, Solubility and Diffusion Coefficient of Carbon Dioxide in Biodegradable Polymers, Ind. Eng. Chem. Res. 39 (2000) 4813-4819. doi:10.1021/ie0001220.

[18] S. Areerat, E. Funami, Y. Hayata, D. Nakagawa, M. Ohshima, Measurement and prediction of diffusion coefficients of supercritical CO2 in molten polymers, Polym. Eng. Sci. 44 (2004) 1915-1924. doi:10.1002/pen.20194.

[19] S.H. Mahmood, M. Keshtkar, C.B. Park, Determination of carbon dioxide solubility in polylactide acid with accurate $\{$ PVT $\}$ properties, J. Chem. Thermodyn. 70 (2014) 13-23. doi:http://dx.doi.org/10.1016/j.jct.2013.10.019.

[20] Y. Sato, T. Takikawa, A. Sorakubo, S. Takishima, H. Masuoka, M. Imaizumi, Solubility and Diffusion Coefficient of Carbon Dioxide in Biodegradable Polymers, Ind. Eng. Chem. Res. 39 (2000) 4813-4819. doi:10.1021/ie0001220.

[21] G. Li, J. Wang, C.B. Park, R. Simha, Measurement of Gas Solubility in Linear / Branched PP Melts, (2007) 2497-2508. doi:10.1002/polb.

[22] Y.G. Li, C.B. Park, H.B. Li, J. Wang, Measurement of the PVT property of PP/CO2 solution, Fluid Phase Equilib. 270 (2008) 15-22. doi:10.1016/j.fluid.2008.05.007. 
[23] H. Park, C.B. Park, C. Tzoganakis, K.H. Tan, P. Chen, Surface Tension Measurement of Polystyrene Melts in Supercritical Carbon Dioxide, Ind. Eng. Chem. Res. 45 (2006) 16501658.

[24] N.R. Pallas, Y. Harrison, An automated drop shape apparatus and the surface tension of pure water, Colloids and Surfaces. 43 (1990) 169-194. doi:10.1016/0166-6622(90)80287E.

[25] H. Park, C.B. Park, C. Tzoganakis, K.-H. Tan, P. Chen, Simultaneous Determination of the Surface Tension and Density of Polystyrene in Supercritical Nitrogen, Ind. Eng. Chem. Res. 47 (2008) 4369-4373. doi:10.1021/ie071472q.

[26] D. Sage, M. Müller, A.F. Stalder, T. Melchior, T. Blu, M. Unser, Low-bond axisymmetric drop shape analysis for surface tension and contact angle measurements of sessile drops, Colloids Surfaces A Physicochem. Eng. Asp. $364 \quad$ (2010) 72-81. doi:10.1016/j.colsurfa.2010.04.040.

[27] M. Wulf, S. Michel, K. Grundke, del Rio OI, D. Kwok, A. Neumann, Simultaneous Determination of Surface Tension and Density of Polymer Melts Using Axisymmetric Drop Shape Analysis., J. Colloid Interface Sci. 210 (1999) 172-181. doi:10.1006/jcis.1998.5942.

[28] S.M.I. Saad, Z. Policova, E.J. Acosta, a W. Neumann, Range of validity of drop shape techniques for surface tension measurement., Langmuir. 26 (2010) 14004-13. doi:10.1021/la1020675.

[29] S.M.I. Saad, Z. Policova, W. Neumann, Design and accuracy of pendant drop methods for surface tension measurement, Colloids Surfaces A Physicochem. Eng. Asp. 384 (2011) 442-452. doi:10.1016/j.colsurfa.2011.05.002.

[30] Y. Sato, M. Yurugi, K. Fujiwara, S. Takishima, H. Masuoka, Solubilities of carbon dioxide and nitrogen in polystyrene under high temperature and pressure, Fluid Phase Equilib. 125 (1996) 129-138. doi:10.1016/S0378-3812(96)03094-4.

[31] M.M. Hasan, Y.G. Li, G. Li, C.B. Park, P. Chen, Determination of Solubilities of CO 2 in Linear and Branched Polypropylene Using a Magnetic Suspension Balance and a PVT Apparatus, J. Chem. Eng. Data. 55 (2010) 4885-4895. doi:10.1021/je100488v.

[32] F. Rouquerol, J. Rouquerol, K.Sing, Adsorption by Powders and Porous Solids Principles, Methodology and Applications, Academic Press, 1998.

[33] H. Park, R.B. Thompson, N. Lanson, C. Tzoganakis, C.B. Park, P. Chen, Effect of temperature and pressure on surface tension of polystyrene in supercritical carbon dioxide., J. Phys. Chem. B. 111 (2007) 3859-68. doi:10.1021/jp065851t.

[34] D. B. Macleod, On a relation between surface tension and density, Trans. Faraday Soc. 19 (1923) 38-41. doi:10.1039/TF9231900038. 